INRA Prod. Anim.,

2014, 27 (4), 317-328

\title{
Les extraits de plantes chez le ruminant : effets sur les fermentations dans le rumen et la qualité lipidique des produits animaux
}

\author{
C. BAYOURTHE ${ }^{2,1,3}$, D. ALI-HAIMOUD-LEKHAL ${ }^{4}$ \\ ${ }^{1}$ INRA, UMR1388 GenPhySE, F-31326 Castanet-Tolosan, France \\ ${ }^{2}$ Université de Toulouse INPT, ENSAT, UMR1388 GenPhySE, F-31326 Castanet-Tolosan, France \\ ${ }^{3}$ Université de Toulouse INPT, ENVT, UMR1388 GenPhySE, F-31076 Toulouse, France \\ ${ }^{4}$ Université de Toulouse, INPT, Ecole d'Ingénieurs de Purpan, F-31076 Toulouse, France
}

Courriel : bayourthe@ensat.fr

Le développement du marché des extraits de plantes (huiles essentielles, tannins condensés, saponines) dans le secteur de l'alimentation animale est en forte progression et pourrait atteindre 100 voire 150 millions d'euros dans les dix prochaines années. Ce développement s'explique d'une part, parce qu'ils constituent une alternative naturelle aux antibiotiques facteurs de croissance interdits dans l'UE depuis 2006 et, d'autre part, en raison de leurs effets sur les performances de production, la qualité des produits, la santé et le bien-être des animaux.

Chez le ruminant, l'efficacité du métabolisme azoté et énergétique pour répondre aux besoins des animaux à haut niveau de production dépend du niveau de la digestion microbienne. La digestion ne pouvant être totale, elle conduit à des pertes azotées dans l'urine ou le lait et à une perte énergétique via la production de méthane, gaz à effet de serre, qui constituent des impacts négatifs sur l'environnement. Aussi, l'objectif des nutritionnistes est de contrôler l'activité de l'écosystème ruminal afin d'optimiser son fonctionnement et de réduire les rejets polluants (azote et méthane) par l'animal pour, in fine, améliorer les performances et la santé de l'animal ainsi que la qualité des produits. Une bonne gestion de l'alimentation doit permettre d'atteindre ces objectifs, mais l'utilisation d'additifs est une clé de contrôle supplémentaire. Les extraits de plantes, en tant qu'alternatives naturelles aux antibiotiques facteurs de croissance, apparaissent comme étant de bons candidats pour réguler le fonctionnement du rumen.

Le terme générique « extraits de plantes », habituellement utilisé, bien que très vague, regroupe des mélanges de molécules obtenues grâce à différentes techniques d'extraction, à partir de végétaux ou parties de végétaux. La nature et la partie du végétal ainsi que le mode d'extraction conditionnent la composition du mélange. Les molécules actives de ces produits, potentiellement utilisables en alimentation des ruminants, sont issues du métabolisme dit secondaire des plantes car elles proviennent de voies différentes de celles essentielles à la vie, que sont la photosynthèse, la glycolyse ou encore la synthèse des acides aminés. Les extraits de plantes peuvent être de nature phénolique comme les tannins, ou de nature terpénoïde comme les saponines, voire des deux comme les Huiles Essentielles (HE). Chaque composé se caractérise par une propriété principale pouvant expliquer les différents effets sur le microbiote du rumen : complexation aux protéines, pouvoir bactéricide et défaunant pour les tannins condensés (TCs) (Reed 1995) ; propriétés bactéricide (Ultee et al 2002, Gill et Holley 2004) et antifongique (Chami et al 2004) très importantes pour les HE de nature phénolique et dans une moindre mesure pour celles de nature terpénoïde ; complexation aux protéines et pouvoir défaunant pour les saponines (Valdez et al 1986, Diaz et al 1993). Dans cet article seront passés en revue les effets des tannins condensés, des HE et des saponines sur le microbiote et les fermentations dans le rumen. Dans une dernière partie, les conséquences sur la qualité lipidique des produits seront analysées.

\section{1 / Les tannins condensés}

Les TCs sont des polymères de haut poids moléculaire caractéristiques des plantes ligneuses (acacia, chêne, châtaignier) et des légumineuses fourragères, des zones tempérées (sulla, lotier, sainfoin) et tropicales (Leucaena leucoce- phala). Ils sont constitués de monomères (unité flavonoïde) capables de former des complexes avec les protéines, le nombre de monomères déterminant le degré de polymérisation du tannin. La distribution des monomères qui composent les TCs est variable selon les espèces et les genres. Par exemple, les TCs du lotier corniculé (Lotus corniculatus) sont principalement constitués d'épicatéchines $(65 \%$ des TCs totaux) alors que dans les TCs du lotier pédonculé (Lotus pedunculatus), les épigallocatéchines sont dominantes $(65 \%$ des TCs totaux). Les TCs du trèfle violet (Trifolium pratense) sont composés majoritairement d'épicatéchines (80\% des TCs totaux) alors que ceux du trèfle blanc (Trifolium repens) contiennent un mélange de gallocatéchines et d'épigallocatéchines (respectivement 40 et $55 \%$ des TCs totaux) (Foo et al 1997, Sivakumaran et al 2004).

\section{1 / Effets sur le microbiote du rumen}

L'action des TCs sur les microorganismes du rumen est variable en fonction de leur structure physico-chimique (composition et degré de polymérisation) et/ou de la dose utilisée. Ainsi, à dose identique, les TCs de la Dorycnie dressée (Dorycnium rectum) $(50 \%$ de gallocatéchines et $42 \%$ de catéchines) réduisent de $25 \%$ seulement la croissance spécifique de Ruminococcus albus contre $75 \%$ pour les TCs extraits de Lotus corniculatus (65\% dépicatéchine et $30 \%$ d'épigallocatéchine) (Sivakumaran et al 2004, Min 
et al 2005). L'effet inhibiteur des TCs de Dorycnium rectum semble plus important pour des fractions de faible $(3300 \mathrm{Da})$ et moyen (12200 Da) poids moléculaire (PM) que pour une fraction de haut PM (35600 Da) (Sivakumaran et al 2004). De façon générale, la croissance bactérienne est d'autant plus inhibée que la concentration en TCs dans le milieu est élevée. Toutefois, certaines espèces bactériennes seraient tannins-tolérantes, en raison de leur capacité à modifier ou dégrader les tannins (Smith et al 2005). A titre d'exemple, la croissance de Streptococcus bovis est maintenue pour des concentrations en TCs extraits du Lotus corniculatus allant jusqu'à $400 \mu \mathrm{g} / \mathrm{mL}$ alors que Prevotella ruminicola ne se développe pas au-delà de la dose de $100 \mu \mathrm{g} / \mathrm{mL}$; cette différence de sensibilité se retrouvant aussi entre souches de même espèce (Min et al 2005). Dans le même sens, Sivakumaran et al (2004) montrent que les concentrations inhibitrices en TCs de Dorycnium rectum sont supérieures à $300 \mu \mathrm{g} / \mathrm{mL}$ pour Clostridium amilophilus, comprises entre 100 et $200 \mu \mathrm{g} / \mathrm{mL}$ pour Clostridium proteoplasticum, Ruminococcus albus et Butyrivibrio fibrisolvens, et inférieures à $100 \mu \mathrm{g} / \mathrm{mL}$ pour Peptostreptococcus anaerobius. Les TCs auraient aussi un effet sur les archées méthanogènes. Ainsi, récemment, Min et al (2013) ont observé un effet négatif des TCs d'écorce de pin sur certaines populations d'archées comme Methanobrevibacter et Methanobacteriaceae et au contraire positif sur d'autres telles Akkermansia et Methanosphaera et, ce, quelle que soit la dose $(0,17,1,6$ et $3,3 \%$ de la MS de la ration) utilisée.

\section{2 / Effets sur les fermentations dans le rumen}

Des travaux conduits in vitro (Tavendale et al 2005, Getachew et al 2008) et in vivo (Puchala et al 2005, Beauchemin et al 2007, Animut et al 2008) montrent généralement que les TCs conduisent à une diminution de la concentration en azote ammoniacal $\left(\mathrm{N}-\mathrm{NH}_{3}\right)$ dans le milieu ruminal mais n'affectent pas la concentration en Acides Gras Volatils totaux (AGVt). Ceci s'explique par la capacité des TCs $i$ ) à se lier aux protéines alimentaires, les protégeant ainsi de l'attaque microbienne et $i$ ) à inhiber la croissance des bactéries protéolytiques. Il semblerait qu'à dose élevée, l'effet soit plus marqué in vitro qu'in vivo et qu'à dose identique, l'amplitude de la réponse soit différente selon la source de TCs (figure 1). L'essai de Cortes et al (2009), conduit in vitro, confirme ces résultats. En effet, l'incubation de tourteau de soja en présence de doses croissantes de TCs $(300,600$ et $900 \mathrm{mg} / \mathrm{g}$ de protéines de substrat), extraits de Flemingia macrophylla, de calliandra (Calliandra

Figure 1. Relation entre la dose et la nature des tannins condensés et la diminution de la concentration en azote ammoniacal (d'après Puchala et al 2005 ; Tavendale et al 2005 ; Beauchemin et al 2007 ; Animut et al 2008 ; Getachew et al 2008).

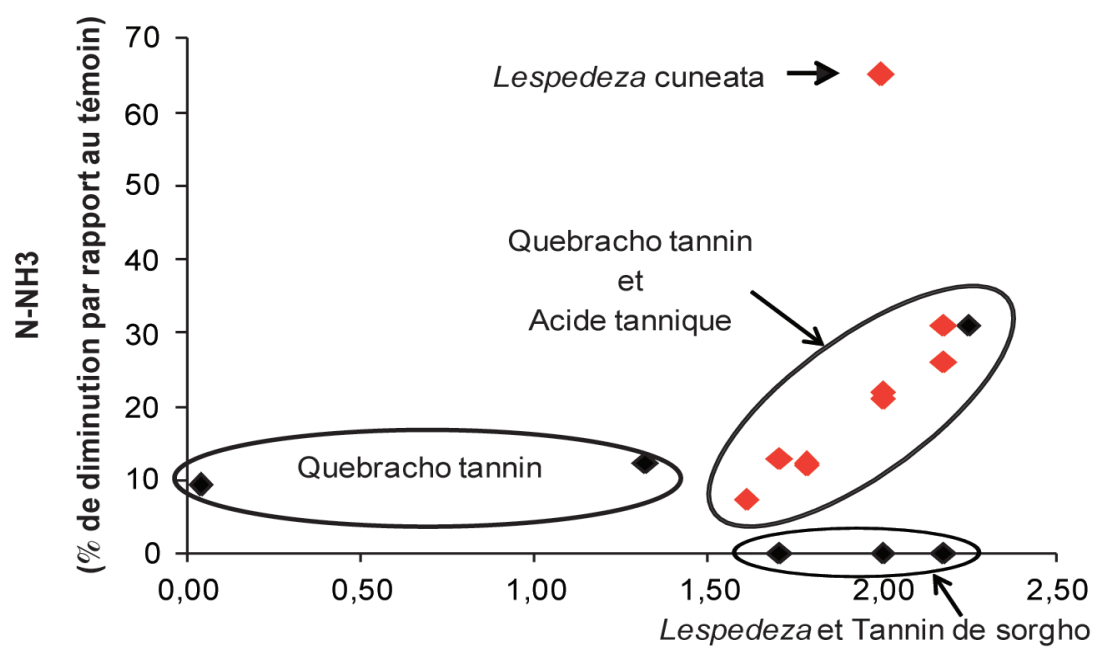

Dose de tannins condensés [exprimée en log (dose +1)]

$\diamond$ Essais in vitro ; Essais in vivo.

calothyrsus) ou encore de leucaena (Leucaena leucocephala), conduit à une baisse de la production de $\mathrm{N}-\mathrm{NH}_{3}$ (de 40 à $90 \%$ ) et de la dégradation des protéines (de 25 à 65\%) dans le milieu. Cette moindre dégradation des protéines dans le rumen ne s'accompagne pas d'une meilleure digestion post-rumen et, ce, quelle que soit la teneur en TCs de la plante. Ceci confirme le rôle important de la composition chimique et de la structure des tannins dans leur capacité à former des complexes plus ou moins stables dans les compartiments digestifs et, très certainement, l'influence du $\mathrm{pH}$ sur cette complexation. La diminution de la dégradation des protéines dans le rumen conduit à une augmentation de la quantité d'azote non ammoniacal atteignant le duodénum comme le montre la figure 2. Cette augmentation est essentiellement due à une augmentation du flux d'azote d'origine alimentaire, le flux d'azote microbien étant peu modifié. Ce qui montre aussi que, dans la gamme de teneurs en TCs des plantes testées dans ces essais, les TCs ne limitent pas la synthèse microbienne.

En ce qui concerne l'action des TCs sur la méthanogenèse, l'effet généralement observé, tant in vitro qu'in vivo, est une

Figure 2. Relation entre la teneur en tannins condensés et les flux duodénaux d'azote non ammoniacal et microbien (d'après Barry et Manley 1984 ; Barry et al 1986 ; Waghorn et al 1987, 1994 ; McNabb et al 1996 ; Wang et al 1996 ; Bermingham et al 2001 ; Min et al 2002, 2003).

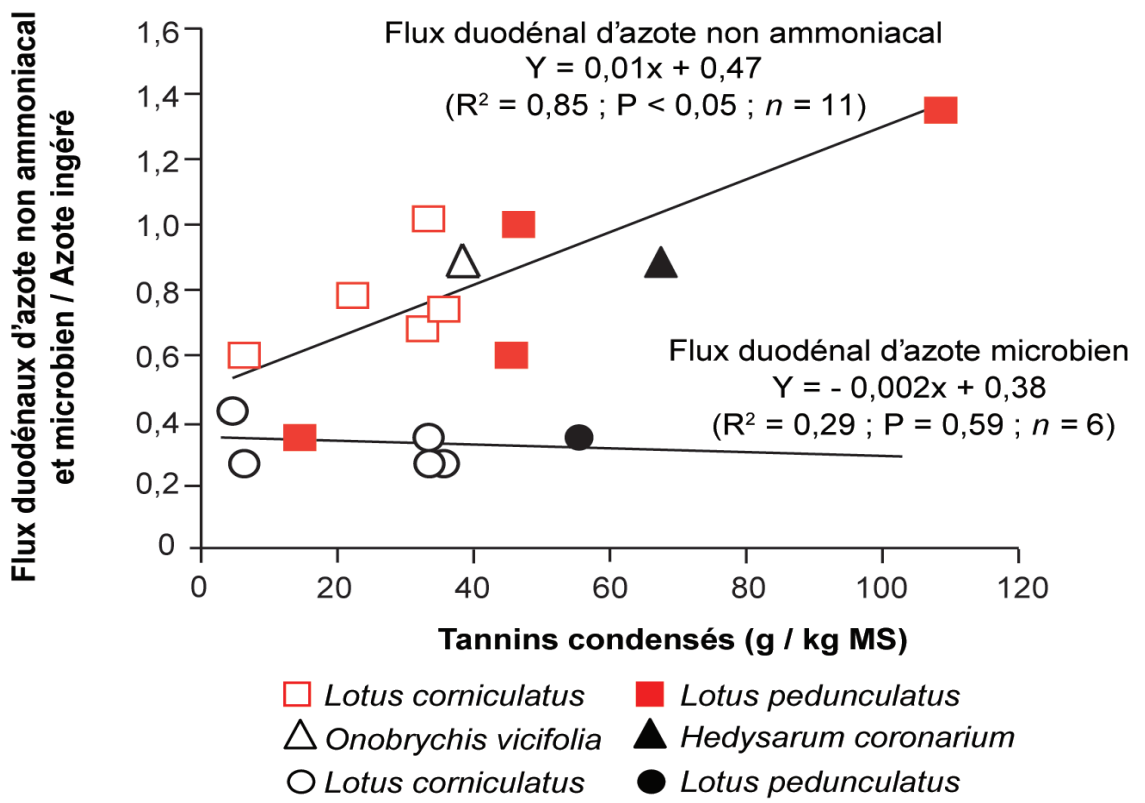


diminution de la production de $\mathrm{CH}_{4}$ (Jayanegara et al 2011) bien que l'amplitude de la réponse soit variable et dépende de plusieurs facteurs que les études in vitro permettent de mieux cerner. Le premier facteur de variation est la durée de l'incubation en présence de TCs qui exerce une action sur la durée d'adaptation des microorganismes à ces extraits de plante. Plus la durée d'incubation est longue plus la réponse, c'est-à-dire la réduction de la méthanogenèse, est limitée : - 26, - 24 et - $16 \%$ respectivement pour des essais conduits en cultures batch après $12 \mathrm{~h}$ d'adaptation, en gaz test après $24 \mathrm{~h}$ d'adaptation et en Rusitec après 12 jours d'adaptation (Patra et Saxena 2011). Le deuxième facteur pourrait être la teneur en TCs totaux de la plante (Jayanegara et al 2009) comme récemment observé par Naumann et al (2013). Dans cet essai, la production de méthane in vitro est plus faible en présence de TCs d'Acacia angustissima (contenant 8,1 à $8,9 \%$ de TCs) qu'en présence de TCs de Leucaena retusa (contenant 3,2\% de TCs). Enfin, l'effet serait dose dépendant avec une action limitée sur les fermentations ruminales, ce qui conduit à penser que les TCs auraient un effet direct sur les archées méthanogènes (Popova et al 2011, Tan et al 2011).

Pour ce qui est de l'effet de la structure chimique des TCs sur la méthanogenèse, les quelques résultats disponibles sont contradictoires. Huang et al (2011) avaient montré que la réduction de la méthanogenèse était d'autant plus importante que le PM des TCs était élevé (-21,5, - 54,7 et $-61,9 \%$ pour des PM respectifs de $490 \mathrm{Da}, 857 \mathrm{Da}$ et $1349 \mathrm{Da})$. En revanche, Naumann et al (2013) n'ont pas établi de relation linéaire entre la production in vitro de méthane et le poids moléculaire de différents TCs testés qui variait de $552 \mathrm{Da}$ (Leucaena retusa) à $1483 \mathrm{Da}$ (Lespedeza cuneata).

\section{2 / Les huiles essentielles}

Les HE sont composées d'un mélange complexe de molécules aromatiques volatiles, liposolubles mais non lipidiques. On les trouve dans tout le règne végétal, et dans tout type d'organe : fleurs (camomille), fruits (citron), graines (cumin), feuilles (eucalyptus, citronnelle), écorces (cannelier), bois (santal, bois de rose), rhizome (curcuma), racine (angélique), plante entière fleurie (origan). Les plantes dites « aromatiques » synthétisent ces mélanges de molécules aromatiques (cf. encadré), spécifiques de la plante et de l'organe considéré, dans des cellules sécrétrices localisées dans l'épiderme (pétales de rose), dans des poils sécréteurs (feuilles de sauge) ou des cellules internes comme l'écorce de cannelier

\section{Encadré. Voies de synthèse des huiles essentielles.}

Il existe deux voies de synthèse au sein des cellules sécrétrices de la plante qui donnent naissance à deux grands groupes chimiques dans lesquels on peut classer les molécules des Huiles Essentielles (HE).

1- La voie des terpénoïdes (composés dits « terpéniques ») : tous les terpénoïdes sont synthétisés par condensation de l'isopenténylpyrophosphate (IPP) et son isomère allylique, le dimethylallyl diphospate (DMAPP). L'addition d'une unité IPP au DMAPP donne le geranyldiphosphate $\left(\mathrm{C}_{10}\right)$, l'addition de deux unités IPP donne le farnesyl-diphosphate $\left(\mathrm{C}_{15}\right)$, et enfin l'addition de 3 unités IPP au DMAPP donne le geranylgeranyl-diphosphate $\left(C_{20}\right)$. Ces molécules sont aliphatiques ou cycliques et sont constituées uniquement de carbone et d'hydrogène. On trouve essentiellement des monoterpènes dérivés du geranyl-diphosphate dans les HE. La transformation en terpénoïde se fait par oxydation. Les monoterpènes des HE peuvent ainsi, en fonction du degré d'oxydation, avoir les fonctions chimiques suivantes alcool, aldéhyde, acide, ester, cétone ou oxyde. Un noyau benzénique hydroxylé est un phénol, un phénol méthylé est un phénol méthyl éther.

2- La voie des phénylpropanoïdes (composés dits " aromatiques ») : la molécule à l'origine est le phénylpropane, composé d'un cycle aromatique et d'une chaîne latérale à 3 carbones. L'eugénol (phénol) et l'aldéhyde cinnamique (aldéhyde) sont synthétisés par cette voie - il s'agit aussi de la voie de synthèse de la lignine et des tannins condensés (Hoffmann 2003).

Figure 3. Structure chimique de quelques molécules aromatiques d'huiles essentielles (d'après Dorman et Deans 2000, Ultee et al 2002) expliquant leur pouvoir bactéricide.
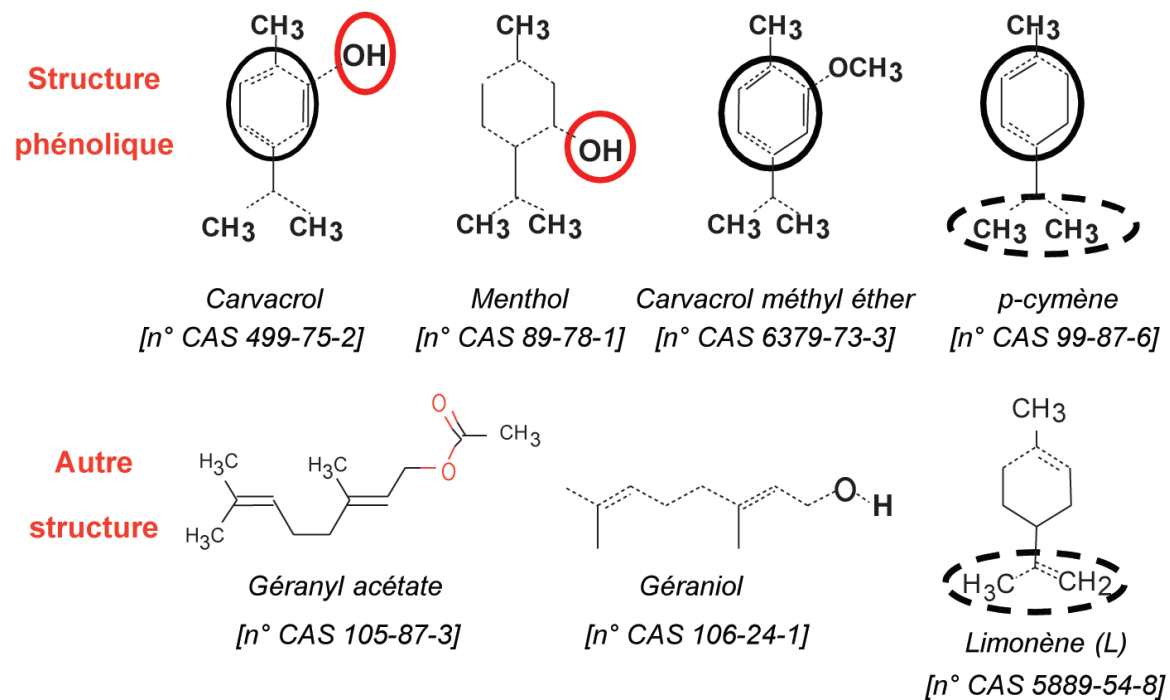

(Franchomme et al 1990, Abdelkouddousse 1991).

\section{1 / Effets sur le microbiote du rumen}

Le pouvoir bactéricide des HE est lié à la structure chimique (Dorman et Deans 2000, Ultee et al 2002) des molécules aromatiques (figure 3) qui les composent. Ainsi, l'activité antimicrobienne particulièrement importante des phénols est due à la présence d'un cycle phénolique et/ou d'un groupement hydroxyle. Ceci explique pourquoi l'activité bactéricide du carvacrol est supérieure à celles du carvacrol-méthylester et du para-cymène qui ne disposent pas du groupement $-\mathrm{OH}$ et à celle du menthol qui ne contient pas de cycle phénolique. La présence d'acétate accroît l'activité des composés d'HE. Ainsi, le géranyl-acétate est plus actif que le géraniol. Lorsque la structure chimique n'est pas de nature phénolique, l'activité dépend de la nature de la chaîne alkyle : les composés disposant d'une chaîne alkényle (e.g. le limonène) sont plus actifs que ceux disposant d'une chaîne alkyle (e.g. le para-cymène). La stéréochimie est, elle aussi, importante : les isomères bêta ont une activité bactéricide contrairement aux isomères alpha (bêta pinène $v s$ alpha pinène); de même, les isomères trans sont actifs contrairement aux cis, e.g. nérol vs géraniol. Ainsi, en fonction du rôle clé de la structure chimique dans le pouvoir antimicrobien des $\mathrm{HE}$, il est possible de les classer par ordre décroissant d'activité bactéricide/ bactériostatique vis-à-vis de bactéries pathogènes (tableau 1).

Busquet et al (2006) ont testé en culture batch, l'HE d'anis (Pinpinella anisum, 86\% d'anéthol), de cade (Juniperus oxycedrus, $35 \%$ d'alpha pinène), d'écorce 
de cannelier (Cinnamonum cassia, 59\% de cinnamaldéhyde), de clou de girofle (Syzygium aromaticum, 85\% d'eugénol), d'aneth (Anethum graveolens, $47 \%$ de carvone), d'origan (Origanum vulgare, $69 \%$ de carvacrol) et d'arbre à thé (Melaleuca alternifolia, $42 \%$ de terpinène4-ol). L'effet inhibiteur de ces HE à la dose de 3000 ppm sur les bactéries du rumen a été évalué via la mesure de la production d'AGVt dans le milieu. En fonction de la diminution de la production observée, les HE se classent comme suit de la plus à la moins inhibitrice : origan $>$ clou de girofle $>$ écorce de cannelier $>$ anis $>$ arbre à thé $>$ cade $>$ aneth. Ce qui donne, compte tenu de la famille chimique à laquelle appartient l'HE : phénol $>$ cinnamaldéhyde $>$ phénol méthylether $>$ monoterpénol $>$ cétone $>$ terpène hydrocarboné ; ce classement confirmant celui établi pour les bactéries pathogènes (tableau 1).

L'effet d'un mélange de composés aromatiques sur des cultures pures de bactéries du rumen (McIntosh et al 2003) a été étudié par la mesure de la concentration inhibitrice 50 (CI50), concentration permettant une diminution de la densité cellulaire de $50 \%$ au bout de $24 \mathrm{~h}$ d'incubation. Ajouté au milieu de culture, ce mélange contenant 15 à 33,5\% de phénols (5-10\% de crésol et résorcinol ; 5-10\% thymol ; $2-4,5 \%$ guaiacol ; $1-3 \%$ eugénol ; $2-6 \%$ vanilline) inhibe la croissance de la plupart des cultures pures bactériennes à des concentrations inférieures à 100ppm.
Les résultats montrent que Streptococcus bovis est l'espèce la plus résistante, et que Prevotella ruminicola, Clostridium sticklandii, et Peptostreptococcus anaerobius sont les plus sensibles. Quelques espèces, incluant Prevotella ruminicola et Prevotella bryantii, s'adaptent et sont capables de croître à des concentrations plus élevées d'HE, alors que d'autres, incluant Clostridium sticklandii et Peptostreptococcus anaerobius, restent encore sensibles. Ces deux dernières espèces font partie de celles identifiées comme des bactéries « hyper productrices d'ammoniac ». Cette adaptation aux HE pourrait expliquer la diminution voire l'absence d'effet souvent observé in vivo. Plus récemment, Patra et Yu (2013) ont montré in vitro que les $\mathrm{HE}$ d'origan, d'ail et de menthe, utilisées à la dose de $0,50 \mathrm{~g} / \mathrm{L}$ de milieu de fermentation, affectaient les communautés bactériennes. Si les trois HE stimulent le développement des Prevotellaceae, elles ont des effets différents sur les Lachnospiraceae et les Ruminococcaceae : l'HE d'origan favorise l'occurrence des Lachnospiraceae et diminue celle des Ruminococcaceae, contrairement à l'HE d'ail et l'HE de menthe qui diminuent l'occurrence de ces deux familles bactériennes.

D'études conduites in vivo, il ne ressort pas d'effet marqué d'un mélange d'HE $\left(\right.$ Crina $\left.^{\circledR}\right)$ (Newbold et al 2004, Benchaar et al 2006, Benchaar et al 2007) ou d'un mélange cinnaladéhyde/eugenol (Cardozo et al 2006) sur le nombre et/ou l'activité bactériolytique (McIntosh et al 2003) des protozoaires ciliés. Des résultats plus récents (Benchaar et al 2008) ont aussi montré que l'aldéhyde cinnamique restait sans effet sur le nombre total de protozoaires, mais aussi sur le nombre de Dasytricha, Diplodinium, Entodinium et Polyplastron. Cardozo et al (2006) ont tout de même observé qu'un mélange d'aldéhyde cinnamique et d'eugénol (2:1) augmentait le nombre de protozoaires holotriches sans influence sur les protozoaires entodiniomorphes alors que l'extrait d'anis diminue ces deux populations.

Les données sur les archées méthanogènes sont très limitées. On pourra citer les travaux de Ohene-Adjei et al (2008) qui ont observé que l'HE d'ail ingérée par des agneaux à la dose de $200 \mathrm{mg} / \mathrm{kg}$ de matière sèche ingérée n'affectait pas significativement le nombre total de copies d'archées méthanogènes, mais augmentait leur diversité et notamment l'occurrence de deux clusters : Methanosphaera stadtmanae et Methanobrevibacter smithii. L'augmentation de la diversité des méthanogènes pourrait être le reflet de la capacité de ces microorganismes à s'adapter aux composés aromatiques.

\section{2 / Effets sur les fermentations dans le rumen}

Sur la base du classement présenté au tableau 1, Noirot et al (2007) ont réalisé une analyse quantitative de la bibliogra-

Tableau 1. Classement des huiles essentielles et de leurs composés aromatiques selon leur pouvoir bactéricide vis-à-vis de bactéries pathogènes (d'après Belaiche 1979, Knobloch et al 1989, Dogna 1990, Franchomme et al 1990, Inouye et al 2001, Friedman et al 2002, Hernandez Ochoa et Vilarem 2005).

\begin{tabular}{|l|l|l|l|}
\hline Rang' & Famille chimique & Huile essentielle & Composé aromatique \\
\hline 1 & Phénol & $\begin{array}{l}\text { Thym, Sarriette, Origan } \\
\text { Clou de girofle, Feuilles de cannelle } \\
\text { Bois de Gaïac }\end{array}$ & $\begin{array}{l}\text { Carvacrol, Thymol } \\
\text { Eugénol } \\
\text { Gaïacol }\end{array}$ \\
\hline 1 & Aldéhyde & Ecorce de cannelle & Cinnamaldéhyde \\
\hline 2 & Monoterpénol & Arbre à thé & 1-terpinène-4-ol \\
\hline 3 & Aldéhyde & Citronnelle & Géranial-néral, Citronellal \\
\hline 4 & Cétone & $\begin{array}{l}\text { Romarin à verbénone } \\
\text { Menthe } \\
\text { Aneth }\end{array}$ & $\begin{array}{l}\text { Verbénone } \\
\text { Menthone } \\
\text { Carvone }\end{array}$ \\
\hline 5 & Ether & $\begin{array}{l}\text { Basilic, Estragon } \\
\text { Anis, Badiane }\end{array}$ & $\begin{array}{l}\text { Estragol } \\
\text { Anéthol }\end{array}$ \\
\hline 6 & Oxyde & Eucalyptus & Eucalyptol \\
\hline 7 & Terpène & Pin, Sapin & Pinène \\
\hline
\end{tabular}

${ }^{1}$ ordre décroissant: du rang 1 (le plus bactéricide / bactériostatique) au rang 7 . 
Tableau 2. Variation estimée de la concentration en acides gras volatils totaux, du $\mathrm{pH}$, de la concentration en ammoniac et en acétate dans le milieu de fermentation en fonction de la dose d'huile essentielle ${ }^{1}$ (d'après Noirot et al 2007).

\begin{tabular}{|c|c|c|c|}
\hline & ETR & $\mathbf{R}^{2}$ & $\mathbf{P}$ \\
\hline \multicolumn{4}{|c|}{$\begin{array}{l}\text { Phénols, aldéhyde cinnamique, terpènes hydrocarbonés (alpha pinène) ou oxygénés avec une fonction éthe } \\
\text { (anéthol), alcool (terpinène-4-ol), cétone (carvone) ou ester (salicylate de benzyle), et HE contenant } \\
\text { majoritairement ces molécules aromatiques }\end{array}$} \\
\hline$\triangle A G V t=-2,84-12,2 \log (\text { dose }+1)^{2}$ & 2,0 & 53,9 & $<0,001$ \\
\hline \multicolumn{4}{|c|}{ Phénols, aldéhyde cinnamique, et $\mathrm{HE}$ contenant majoritairement ces molécules aromatiques } \\
\hline$\triangle \mathrm{pH}=0,075+0,766 \log ($ dose +1$)$ & 6,7 & 69,6 & $<0,001$ \\
\hline$\triangle \mathrm{N}-\mathrm{NH}_{3}=6,2-50,4 \log (\text { dose }+1)^{2}$ & 3,2 & 70,7 & $<0,001$ \\
\hline \multicolumn{4}{|c|}{$\begin{array}{l}\text { Terpènes hydrocarbonés (alpha pinène) ou oxygénés avec une fonction éther (anéthol), alcool (terpinène-4- } \\
\text { ol), cétone (carvone) ou ester (salicylate de benzyle), et HE contenant majoritairement ces molécules } \\
\text { aromatiques }\end{array}$} \\
\hline$\Delta C_{2}=-0,0245-1,1 \log ($ dose +1$)$ & 1,2 & 49,5 & $<0,001$ \\
\hline
\end{tabular}

${ }^{1}$ La dose du produit testé, allant de 0,001 à $9 \%$ de l'aliment ou de la matière première utilisée comme substrat, a été transformée en log (dose +1$)$ afin d'accorder moins de poids aux doses les plus élevées.

$\mathrm{AGVt}=$ Acides Gras Volatils totaux $(\mathrm{mmol} / \mathrm{L}) ; \mathrm{N}-\mathrm{NH}_{3}=\operatorname{ammoniac}(\mathrm{mg} / \mathrm{L}) ; \mathrm{C}_{2}=$ acétate $(\%$ des AGVt).

phie relative aux effets des HE et de leurs composés sur différents paramètres fermentaires (concentration en AGVt, proportions d'acétate et de propionate, concentration en ammoniac et $\mathrm{pH})$. Deux groupes de produits ont été comparés : l'un contenant les produits les plus antibactériens c'est-à-dire les phénols, l'aldéhyde cinnamique et les produits essentiellement composés de ces molécules aromatiques ; l'autre constitué de terpènes hydrocarbonés (alpha pinène) ou de terpènes oxygénés avec une fonction éther (anéthol), alcool (terpinèn-4-ol), cétone (carvone) ou ester (salicylate de benzyle). Cette analyse a permis d'établir des équations de prédiction de la réponse en fonction de la nature chimique et de la dose d'HE (tableau 2). Les produits des deux groupes ont entraîné une augmentation du $\mathrm{pH}$ du milieu par rapport aux témoins, bien que les écarts observés variaient avec la dose de produit. Ainsi, plus la dose de phénols ou de cinnamaldéhyde augmente, plus le pH est élevé. Cet effet peut s'expliquer par la diminution de la concentration en AGVt du milieu, de même intensité quelle que soit la nature de la molécule. L'effet de la dose sur les AGVt était de nature quadratique. Seuls les phénols et le cinnamaldéhyde diminuent la concentration en $\mathrm{N}-\mathrm{NH}_{3}$ alors que les autres molécules n'ont pas eu d'effet sur ce paramètre. La concentration en ammoniac était négativement liée par régression, de manière quadratique, à la dose avec les phénols et le cinnamaldéhyde.
L'hypothèse d'un effet nature de la ration sur la réponse obtenue avec les HE ne peut toutefois être écartée comme semble le montrer l'essai de Noirot et Bayourthe (2008). Dans cet essai, il s'agissait de mesurer les effets de deux mélanges d'HE à base de carvacrol ou de cinnamaldéhyde sur la dégradation dans le rumen de différentes matières premières riches en protéines (soja), en amidon (maiis) ou en parois végétales (luzerne), chez des vaches laitières recevant deux

types de ration : une riche en fibres $(42 \%$ de NDF) et une riche en amidon (42\% d'amidon). La figure 4 montre que le mélange à base de cinnamaldéhyde conduit à une réduction significative de la dégradation dans le rumen de l'amidon de maïs, quelle que soit la nature de la ration, mais de façon plus marquée avec une ration enrichie en fibres. Il entraîne aussi, avec la même intensité, une diminution de la dégradation de la ligno-cellulose, que le mélange soit apporté dans une ration

Figure 4. Effet d'un apport oral de composés aromatiques chez la vache laitière sur la dégradation dans le rumen (en écart par rapport au témoin) des protéines, des fibres et de l'amidon en fonction de la nature de la ration (Noirot et Bayourthe 2008).

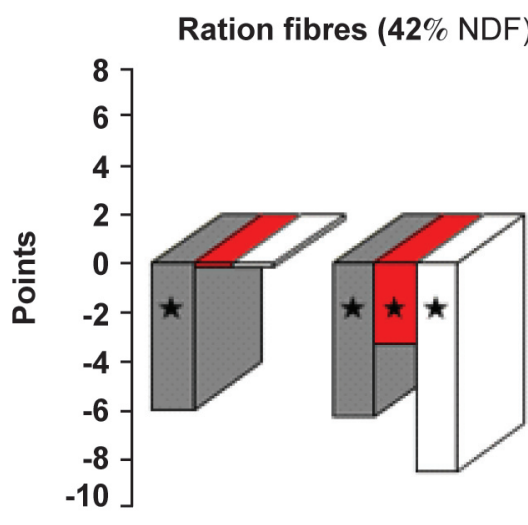

Carvacrol Cinnamaldéhyde

\section{Ration amidon (42\% amidon)}

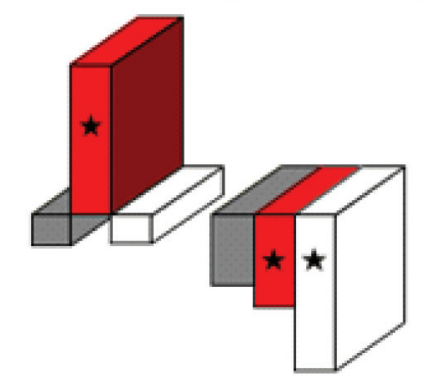

Carvacrol Cinnamaldéhyde

\section{Protéines}

ADF
Amidon
* : Variation significative par rapport au témoin $(P<0,05)$; ADF : « Acid Detergent Fiber ». 
fibreuse ou riche en amidon. En revanche, avec un mélange à base de carvacrol, la dégradation de la ligno-cellulose est stimulée mais uniquement avec une ration concentrée en énergie. Les deux mélanges permettent de réduire, dans le cas d'une ration fibreuse, la dégradation des protéines de soja de l'ordre de $6 \%$ en moyenne. Ainsi, le carvacrol semblerait plus intéressant à associer à une ration concentrée en énergie, alors que le cinnamaldéhyde valoriserait mieux une ration riche en fibres.

De récents travaux indiquent que les HE d'ail, de thym, d'origan et de cannelle peuvent diminuer in vitro la production de $\mathrm{CH}_{4}$ pour des doses relativement élevées, généralement supérieures à $300 \mathrm{mg} / \mathrm{L}$. Busquet et al (2005) ont été les premiers à rapporter in vitro les effets de l'HE d'ail et d'un de ses composés, le diallyl disulfide (DAD), sur la production de $\mathrm{CH}_{4}$. Ajoutés à la dose de $300 \mathrm{mg} / \mathrm{L}$, l'HE d'ail et le DAD réduisent la production de $\mathrm{CH}_{4}$ avec la même intensité, suggérant dès lors que ce composé soufré est en partie responsable de l'effet observé, probablement par action directe sur les méthanogènes via l'inhibition de la 3hydroxy-3-methylglutaryl coenzyme A réductase, enzyme clé de la synthèse des éthers isoprénoïdes, principaux composants de la membrane cellulaire des archées. Toutefois, ces effets n'ont pas été rapportés in vivo (Doreau et al 2011).

Plus récemment, Macheboeuf et al (2008) ont montré in vitro que la production de $\mathrm{CH}_{4}$, non affectée par l'apport d'HE d'Origanum vulgare $(89 \%$ de carvacrol et $5 \%$ de thymol) jusqu'à la concentration de $300 \mathrm{mg} / \mathrm{L}$, était fortement inhibée $(-63 \%)$ à partir d'une dose de $450 \mathrm{mg} / \mathrm{L}$; dose à laquelle l'HE s'est révélée moins efficace que son principal composant (-85\%), suggérant que des composants mineurs présents dans cette HE pourraient agir de façon antagoniste avec le carvacrol. Testée dans les mêmes conditions, l'HE de cannelle (79\% de cinnamaldéhyde) inhibe presque complètement la méthanogenèse (- 98\%) à une concentration de $500 \mathrm{mg} / \mathrm{L}$ alors que le cinnamaldéhyde pur, utilisé à la même dose, ne la réduit que de $19 \%$. L'activité antiméthanogène plus prononcée de l'HE que de son principal composant, pourrait être expliquée par une interaction entre le cinnamaldéhyde et d'autres composés aromatiques présents en faible concentration comme l'eugénol, par exemple.

\section{3 / Les saponines}

Les saponines sont des tensio-actifs naturels, à activité membranolytique visà-vis des eucaryotes. Elles sont composées d'une ou plusieurs chaînes hydrophiles (glycone) et d'un noyau lipophile (aglycone ou sapogénine) pouvant être de nature stéroïde ou tri-terpénoïde. Si on trouve des sapogénines de nature stéroïde dans l'avoine, l'aubergine et les graines de tomate, la source la plus connue est le Yucca shidigera. Les sapogénines de nature tri-terpénoïde se trouvent, quant à elles, dans le soja, l'ail, le pois ou encore le tournesol; la source la plus connue étant le bois de panama (Quillaja saponaria).

\section{1 / Effets sur le microbiote du rumen}

En fonction de leur nature, les fractions de saponines n'agissent pas avec la même intensité sur les communautés microbiennes. Ainsi, les saponines contenues dans le fenugrec ( $T$. foenum-graecum) montrent l'effet le plus inhibiteur sur la population de champignons alors que celles contenues dans le sesban (Sesbania sesban) sont les plus inhibitrices vis-à-vis des archées méthanogènes (Goel et al 2008). Ces auteurs ont montré que des fractions de certaines plantes telles le chardon (Carduus pycnocephalus), la knautie des champs (Knautia arvensis), le fenugrec et le sesban, riches en saponines, favorisaient le développement des bactéries fibrolytiques $(+20$ à $+45 \%)$, i.e. Fibrobacter succinogenes et Ruminococcus flavefaciens, au dépend des populations de champignons (-20 à - 60\%) et des bactéries méthanogènes (- 20 à $-78 \%)$. L'effet promoteur sur les bactéries fibrolytiques serait la conséquence d'une stimulation de l'absorption des nutriments par les bactéries et/ou du pouvoir défaunant des saponines (Wina et al 2006 ; Zhou et al 2011) en raison de leur interaction avec les stérols présents dans la paroi des protozoaires ciliés. Toutefois, l'effet promoteur des saponines sur la communauté de bactéries fibrolytiques n'est pas une règle générale. Ainsi, Wina et al (2006) ont montré que les saponines de Sapindus rarak, de nature stéroïdienne, n'affectent pas la croissance de Fibrobacter succinogenes. Cette résistance pourrait s'expliquer par leur capacité à déglycosyler et donc à inactiver les saponines, comme cela avait été démontré pour le yucca par Wang et al (2000). En revanche, les concentrations des bactéries ruminocoques $R$. flavefaciens et $R$. albus diminuent fortement et rapidement dès l'apport de saponines, restant à un niveau très faible même après retrait des saponines, démontrant ainsi un effet inhibiteur spécifique de ces extraits de plante sur ces bactéries. Cet effet inhibiteur n'est plus observé lorsque le traitement est plus long, suggérant par là même que ces bactéries seraient capables de s'adapter, probablement par augmentation de l'épaisseur de leur paroi (Wang et al 2000).

\section{2 / Effets sur les fermentations dans le rumen}

Les essais in vivo concernant les effets des saponines sur les paramètres fermentaires sont assez nombreux. Une analyse factorielle des correspondances multiples a été réalisée à partir des essais répertoriés dans la synthèse de Patra et Saxena (2009). Seuls 29 essais ont été retenus car présentant des résultats à la fois sur le $\mathrm{N}_{-} \mathrm{NH}_{3}$ et les AGVt. Les facteurs dose et nature de la ration ont été pris en considération. Les doses ont été exprimées en log $($ dose +1$)$ pour donner moins de poids aux doses les plus fortes et la ration a été caractérisée par le seul rapport fourrage/concentré. Les résultats montrent que de très faibles doses, i.e. inférieures à $0,13 \mathrm{~g} / \mathrm{kg}$ de MS d'une ration à moins de $50 \%$ de fourrages, n'ont pas d'effet sur les paramètres fermentaires. Des doses plus élevées conduisent généralement à une diminution de la concentration en $\mathrm{N}-\mathrm{NH}_{3}$ dans le milieu

Figure 5. Relation entre la dose de saponines et la diminution de la production de méthane (\% du témoin) mesurée in vitro (adapté de Patra et Saxena 2010).

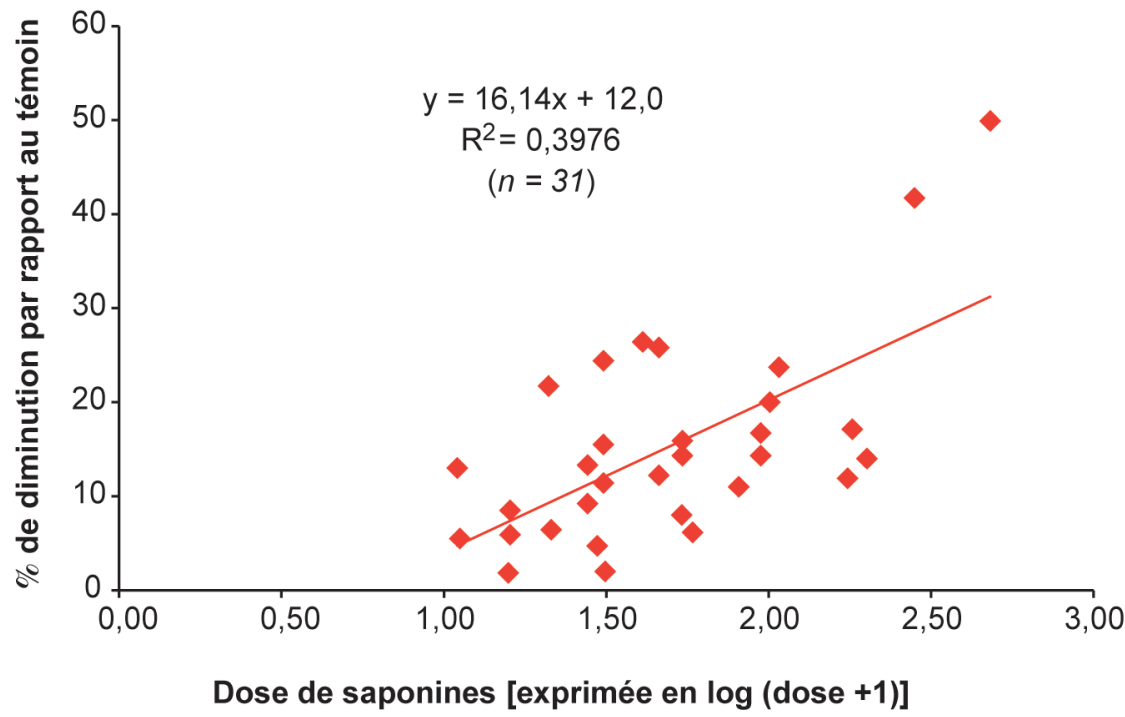


en raison d'une inhibition des uréases (Ellenberger et al 1985), et/ou d'une liaison de la fraction glycone à $\mathrm{l}^{\prime} \mathrm{N}-\mathrm{NH}_{3}$ (Wallace et al 1994), et/ou d'une moindre lyse bactérienne (Wallace et McPherson 1987), et/ou d'une inhibition des activités protéolytique et de désamination (Hristov et al 1999, Singer et al 2008). Une augmentation de la concentration en AGVt est observée pour des doses comprises entre 0,2 et $8 \mathrm{~g} / \mathrm{kg}$ de MS de ration alors qu'une dose supérieure à $10 \mathrm{~g} / \mathrm{kg}$ de $\mathrm{MS}$ d'une ration contenant 50 à $70 \%$ de fourrages entraîne une baisse de cette concentration. L'analyse des données montre, aussi, que la nature de la ration ne serait pas sans influence sur l'amplitude de la réponse observée, comme l'avaient souligné Hess et al (2003). La suppression des protozoaires peut, en partie, expliquer la diminution de la production de $\mathrm{CH}_{4}$ dans la mesure où certaines populations de bactéries méthanogènes restent associées aux protozoaires. Cette réduction de la méthanogénèse est un résultat très souvent observé dans des études in vitro et in vivo (Doreau et al 2011), avec un effet dose dépendant (figure 5) et une réponse variable en fonction de la nature des saponines (Patra et Saxena 2010).

\section{4 / Effets des extraits de plan- tes sur la qualité lipidique des produits}

La viande et le lait sont décriés en raison de leur teneur élevée en Acides Gras Saturés (AGS) : de 46 à $53 \%$ des AG totaux dans la viande (Scollan et al 2006) et de 60 à $65 \%$ des AG totaux dans le lait (Soyeurt et al 2008). Ces AG sont connus pour augmenter les risques cardiovasculaires chez l'Homme (Grant 1998, Huth et al 2006) contrairement aux AG polyinsaturés (AGPI). Le rapport AGS/ AGPI dans les produits de ruminants dépend principalement du remaniement des acides gras dans le rumen. En effet, dans ce pré-estomac, les lipides alimentaires ingérés subissent une lipolyse et certains AGPI libérés, comme le C18:2 $c 9 c 12$ (acide linoléique, $\mathrm{AL}$ ) et le C18:3 $c 9 c 12 c 15$ (acide linolénique, ALN), peuvent être partiellement hydrogénés par les bactéries du rumen au cours d'un processus appelé BioHydrogénation (BH). Au cours de cette BH, des AG intermédiaires sont formés : C18:1t11 (Acide Vaccénique, AV), C18:2 c9t11 (Acide Ruménique, AR) et C18:2 t10c12; l'AV et l'AR présentant des propriétés bénéfiques pour la santé humaine (Shingfield et al 2008). Pour orienter favorablement cette $\mathrm{BH}$ dans le but d'améliorer la qualité du lait ou de la viande, les extraits végétaux, au regard de leur action sur le microbiote ruminal, ont fait l'objet d'un certain nombre d'études depuis les années 2000. Dans cette synthèse, seules les études présentant des profils complets en $\mathrm{AG}$ ont été retenues.

\section{1 / Effets des tannins condensés sur le profil en AG du lait et de la viande}

Même si les TCs sont de plus en plus étudiés pour leurs effets sur la qualité des produits, les données restent limitées, notamment sur le lait, et souvent contradictoires. Chez la brebis laitière pâturant uniquement du sulla - ou sainfoin d'Italie (Hedysarum coronarium) contenant $25 \mathrm{~g}$ de TCs/kg de MS, Cabiddu et al (2009) ont observé une diminution significative (de $40 \%$ en moyenne) des proportions d'AR et d'AV dans le lait et une augmentation concomitante de celle d'AL et d'ALN (de 12 et $30 \%$ respectivement). Lorsqu'un complexant des TCs est apporté sous forme de PolyEthylène Glycol (PEG) dans la ration, des résultats inverses sont obtenus, suggérant ainsi une action inhibitrice de ce type de TCs sur la $\mathrm{BH}$. Chez la même espèce animale
(Toral et al 2011) ainsi que chez la vache laitière (Benchaar et Chouinard 2009), ces effets n'ont pas été confirmés avec des TCs extraits du quebracho (Schinopsis lorentzii). La différence de résultats s'explique sans doute par la nature des TCs utilisés, la durée d'adaptation des animaux, mais aussi par la composition même de la ration. Cette dernière hypothèse avait été avancée par Vasta et al (2009) qui avaient montré que l'apport de $104 \mathrm{~g}$ de TCs extraits de Schinopsis lorentzii augmentait la teneur en C18:1t11 dans le rumen d'agneaux recevant une ration riche en concentré, mais pas dans celui d'animaux recevant la plante entière comme seul composant de la ration, malgré la plus forte concentration en TCs.

Les principaux résultats relatifs à des études portant sur l'effet des TCs sur le profil en $\mathrm{AG}$ de la viande sont présentés dans le tableau 3. Les travaux de Priolo et al (2005) ont mis en évidence dans le muscle longissimus dorsi d'agneau recevant du sulla (Hedysarum coronarium) comme seul aliment $(17,8 \mathrm{~g}$ de $\mathrm{TCs} / \mathrm{kg} \mathrm{MS}$ ) de moindres proportions d'AGS, de C18:2 n-6 et d'AV, mais en revanche des teneurs plus élevées en C18:3 n-3, AR et C18:2 t10c12. Pour une dose plus élevée de TCs (25g/kg MS) apportés sous forme de pulpe de caroube (Ceratonia siliqua) dans une ration concentrée, Vasta et al (2007) montrent que le gras intramusculaire est moins riche en AR et surtout en AV que celui des animaux témoins. Ces derniers résultats n'ont pas été confirmés par Jeronimo et al (2010), pour des rations riches en fourrages ( $90 \%$ de luzerne déshydratée), ni pour une dose comparable de TCs extraits de grains de raisin (Vitis vinifera), ni pour une dose dix fois plus élevée de TCs extraits du ciste à gomme (Cistus ladanifer). Si la nature des TCs peut être à l'origine de la divergence de résultats obtenus, la nature de la ration constitue

Tableau 3. Effet de la teneur en tannins condensés de différentes plantes sur le profil en acides gras (en écart par rapport au témoin) $d u$ Longissimus dorsi chez l'agneau.

\begin{tabular}{|c|c|c|c|c|c|c|}
\hline & $\begin{array}{l}\text { Hedysarum } \\
\text { corona } 1\end{array}$ & $\begin{array}{c}\text { Vitis } \\
\text { vinifera }^{2}\end{array}$ & $\begin{array}{l}\text { Ceratonia } \\
\text { siliqua }^{3}\end{array}$ & \multicolumn{2}{|c|}{$\begin{array}{c}\text { Schinopsis } \\
\text { Iorentzii }^{4}\end{array}$} & $\begin{array}{c}\text { Cistus } \\
\text { ladanifer }\end{array}$ \\
\hline Tannins (g/kg MS) & 17,8 & 25,0 & 27 & $40,4^{(a)}$ & $40,6^{(b)}$ & 250 \\
\hline$\Sigma$ AGS & $-4,4$ & $-0,2$ & $+2,2$ & $-3,6$ & $-1,4$ & $-0,4$ \\
\hline$\Sigma$ AGMI & $+4,2$ & $-2,3$ & $+3,7$ & $-6,4$ & $-0,7$ & $-3,2$ \\
\hline C18:1 c9 & $+5,0$ & $-3,7$ & $+3,9$ & $-6,2$ & $-4,1$ & $-3,9$ \\
\hline C18:1 $t 11$ & $-0,81$ & $+0,03$ & $-0,87$ & $-0,27$ & $+0,63$ & $-0,02$ \\
\hline$\sum$ AGPI & $+0,24$ & $+1,3$ & $-5,9$ & $+10,1$ & $+2,1$ & $+3,1$ \\
\hline C18:2 c9c12 & $-5,9$ & $+2,0$ & $-3,7$ & $-3,7$ & $+1,5$ & $+2,5$ \\
\hline C18:2 c9t11 & $+0,45$ & $-0,02$ & $-0,25$ & $-0,32$ & $+0,50$ & $-0,05$ \\
\hline C18:2 t10c12 & $+0,45$ & $-0,001$ & $+0,01$ & $+0,01$ & $+0,01$ & - \\
\hline C18:3 c9c12c15 & $+3,8$ & $+0,01$ & $-2,0$ & $+1,1$ & $+0,38$ & $-0,59$ \\
\hline
\end{tabular}

${ }^{1}$ Priolo et al $2005 ;{ }^{2}$ Jeronimo et al $2010 ;{ }^{3}$ Vasta et al $2007 ;{ }^{4}$ Vasta et al 2009

(a) Ration $100 \%$ fourrage (Vicia sativa) ; ${ }^{(b)}$ Ration $30 \%$ fourrage / $70 \%$ concentré.

AGS = Acides Gras Saturés ; AGMI = Acides Gras Monolnsaturés ; AGPI = Acides Gras Polylnsaturés.

Les valeurs en rouge indiquent les écarts significatifs par rapport au témoin $(P<0,05)$. 
Tableau 4. Effet de la dose d'huiles essentielles sur le profil en acides gras (en écart par rapport au témoin) du lait de chèvre et de vache.

\begin{tabular}{|c|c|c|c|c|c|c|c|c|c|c|}
\hline \multirow[b]{4}{*}{$\begin{array}{l}\text { Dose ( } \mathrm{mg} / \mathrm{kg} \\
\text { MS ingérée) }\end{array}$} & \multicolumn{5}{|c|}{ Chèvre } & \multicolumn{5}{|c|}{ Vache } \\
\hline & \multirow{2}{*}{\multicolumn{2}{|c|}{$\begin{array}{c}\begin{array}{c}\text { Malecky } \\
\text { et al } 2009^{1}\end{array} \\
\text { Monoterpènes }\end{array}$}} & \multicolumn{3}{|c|}{$\begin{array}{c}\text { Morsy } \\
\text { et al 2012 }\end{array}$} & $\begin{array}{l}\text { Ben } \\
\text { et al }\end{array}$ & $007^{3}$ & $\begin{array}{l}\text { Benchaar } \\
\text { et al } 2006^{3}\end{array}$ & \multirow{2}{*}{\multicolumn{2}{|c|}{$\begin{array}{c}\begin{array}{c}\text { Benchaar } \\
\text { et al 2012 }\end{array} \\
\text { Eugénol }\end{array}$}} \\
\hline & & & \multirow{2}{*}{$\begin{array}{c}\begin{array}{c}\text { Juniperus } \\
\text { oxycedrus }\end{array} \\
1190\end{array}$} & \multirow{2}{*}{$\begin{array}{c}\begin{array}{c}\text { Pimpinella } \\
\text { anisum }\end{array} \\
1400\end{array}$} & \multirow{2}{*}{$\begin{array}{c}\begin{array}{c}\text { Zyzygium } \\
\text { aromaticum }\end{array} \\
1490\end{array}$} & \multicolumn{3}{|c|}{ CRINA $^{\circledR}$} & & \\
\hline & 43 & 430 & & & & 43(a) & $44(b)$ & 89 & $50(a)$ & 50 (b) \\
\hline$\Sigma$ AGS & $-0,24$ & $-0,94$ & $-4,3$ & $-0,35$ & $+0,21$ & $-0,01$ & $+0,62$ & $-0,73$ & $-1,7$ & $+1,4$ \\
\hline$\overline{\Sigma \text { AGMl }}$ & $+0,27$ & $+0,87$ & $+5,1$ & $+0,16$ & $-1,9$ & $-0,04$ & $-1,5$ & $+0,49$ & $+0,05$ & $-1,1$ \\
\hline C18:1 c9 & $+0,26$ & $+0,75$ & $+2,3$ & $+2,1$ & $+2,1$ & $-0,75$ & $-0,15$ & $+0,43$ & $+0,01$ & $-1,0$ \\
\hline C18:1t11 & $+0,09$ & $+0,05$ & ND & ND & ND & $+0,18$ & $-0,10$ & $+0,03$ & $-0,06$ & $-0,04$ \\
\hline$\sum$ AGPI & $+0,03$ & $-0,04$ & $-0,82$ & $+0,94$ & $+2,2$ & $-0,02$ & $+0,98$ & $+0,18$ & $+1,7$ & $-0,30$ \\
\hline C18:2 c9c12 & $+0,02$ & $-0,06$ & ND & ND & ND & ND & ND & ND & $+0,04$ & $+0,03$ \\
\hline C18:2 c9t11 & $-0,01$ & $-0,01$ & $+0,23$ & 0 & 0 & $+0,02$ & $-0,05$ & $+0,05$ & $-0,01$ & $-0,05$ \\
\hline C18:2 t10c12 & ND & ND & $+0,11$ & 0 & 0 & ND & ND & ND & ND & ND \\
\hline C18:3 c9c12c15 & $+0,01$ & $-0,01$ & $+0,25$ & $+0,12$ & $+0,15$ & ND & ND & ND & $+0,03$ & 0 \\
\hline
\end{tabular}

${ }^{1}$ Mélange de monoterpènes : 45,2\% linalool, 36,7\% p-cimène, $16 \% \alpha$-pinène, $2,2 \% \beta$-pinène.

${ }^{2}$ Juniperus oxycedrus : 48,7\% $\alpha$-pinène, $21 \%$ myrcène, 13,4\% limonène ; Pimpinella anisum : $90 \%$ anéthol, $2 \%$ estragol ;

Zyzygium aromaticum : $82 \%$ eugénol, $13 \%$ acétate d'éthyle.

${ }^{3} \mathrm{CRINA}^{\circledR}: 5-10 \%$ crésol, $5-10,5 \%$ thymol, 2-4,5\% guaïacol, 2-6\% vanilline, 1-3\% eugénol ; ration à base d'ensilage de maïs (a) ; ration à base d'ensilage de luzerne $(b)$.

${ }^{4}$ Rapport fourrages/concentrés : 65/35 (a), 35/65 (b)

AGS = Acides Gras Saturés $;$ AGMI = Acides Gras Monolnsaturés $;$ AGPI = Acides Gras Polylnsaturés $;$ ND = Non Déterminé.

Les valeurs en rouge indiquent les écarts significatifs par rapport au témoin $(P<0,05)$.

un autre facteur de variation, bien démontré dans l'étude de Vasta et al (2009). De plus, l'effet inhibiteur exercé sur la BH dans le rumen pourrait provenir d'extraits végétaux primaires ou secondaires, autres que les TCs. En l'état actuel des connaissances, il est impossible de conclure quant à l'effet des TCs sur la qualité de la viande.

\section{2 / Effets des huiles essentielles sur le profil en AG du lait et de la viande}

Concernant les HE, les travaux se sont plus intéressés à l'effet sur la composition en $\mathrm{AG}$ du lait (tableau 4) que sur celle de la viande. Chez la vache laitière, les profils en AG demeurent inchangés sous l'influence d'une supplémentation en HE sous forme de mélange de composés aromatiques tel le CRINA (Benchaar et al 2006, 2007) ou de molécules pures tel l'eugénol (Benchaar et al 2012). Ces résultats sont conformes à ceux obtenus par Malecky et al (2009) chez la chèvre laitière recevant 43 ou 430 ppm d'un mélange de monoterpènes ou encore à ceux de Chaves et al (2008) chez l'agneau en croissance recevant 200 ppm d'aldéhyde cinnamique ou d'HE d'ail ou encore d'HE de genévrier. L'absence d'effet pourrait être liée à l'adaptation des microorganismes du rumen à ces composés (McIntosh et al 2003). Seuls les travaux de Morsy et al (2012) conduits chez la chèvre laitière permettent d'envisager des perspectives intéressantes pour la santé humaine du fait qu'une supplémentation en HE d'anis, de clou de girofle ou de genévrier modifie le profil en AG du lait en faveur de concentrations plus élevées en CLA et en C18:3 n-3.

\section{3 / Effets des saponines sur le profil en AG du lait et de la viande}

Très peu d'études se sont intéressées à l'effet des saponines sur la qualité lipidique du lait et de la viande. Des saponines extraites de Yucca schidigera et utilisées à la dose de $60 \mathrm{~g} / \mathrm{j}$ chez la vache laitière induisent une modification mineure du profil en $A G$, représentée par une réduction des proportions de $\mathrm{C} 6: 0$, de C8:0 et de C18:1t11 (Benchaar et Chouinard 2009).

Chez des agneaux recevant jusqu'à $45 \mathrm{~g}$ de graines de fenugrec, Ben Salem et al (communication personnelle) ont montré des changements limités de la composition en AG du muscle longissimus, suggérant que les saponines du fenugrec peuvent agir sur le métabolisme lipidique. Des saponines extraites de Quillaja saponaria utilisées aux doses de 30,60 ou 90 ppm chez l'agneau ont uniquement conduit à une baisse de la concentration en $\mathrm{C} 14: 1 c 9$ dans la viande (Brogna et al 2011), AG issu de la désatu- ration mammaire du C14:0. Ces mêmes auteurs suggèrent que les saponines pourraient réduire l'accumulation du cholestérol dans la viande à l'instar de leur action chez le monogastrique (Sidhu et Oakenfull 1986). Cet aspect mérite d'être plus étudié au regard de son intérêt potentiel pour la santé humaine.

\section{Conclusion}

L'analyse de la bibliographie montre que beaucoup plus d'études ont été conduites in vitro qu'in vivo pour étudier les effets des extraits de plantes sur les fermentations dans le rumen. Les effets sont variables et souvent contradictoires. Des effets favorables ont été obtenus in vitro, mais sur des durées très courtes et avec des concentrations beaucoup trop élevées pour des applications sur le terrain. Les effets observés ne sont pas forcément aussi marqués, voire absents in vivo, en raison d'une adaptation possible des microorganismes sur le long terme et/ou d'une dégradation des molécules actives par les microorganismes du rumen. Des essais complémentaires conduits in vivo et à long terme restent indispensables pour vérifier les effets observés, dans des conditions d'utilisation plus variées, mais aussi pour s'assurer de l'absence de résidus dans les produits animaux et de leur innocuité pour le consommateur. 


\section{Références}

Abdelkouddousse N., 1991. Huiles essentielles à activités antimicrobiennes. Thèse pour l'obtention du diplôme d'état de docteur en Pharmacie, Université de Clermont-Ferrand I, Faculté de Pharmacie, Clermont-Ferrand, France, 162p.

Animut G., Puchala R., Goetsch A.L., Patra A.K., Sahlu T., Varel V.H., Wells J., 2008. Methane emission by goats consuming diets with different levels of condensed tannins from lespedeza. Anim. Feed Sci. Technol., 144, 212 227.

Barry T.N., Manley T.R., 1984. The role of condensed tannins in the nutritional value of Lotus pedunculatus for sheep. 2. Quantitative digestion of carbohydrate and proteins. Br. J. Nutr., 51, 493-504.

Barry T.N., Manley T.R., Duncan S.J., 1986. The role of condensed tannins in the nutritional value of Lotus pedunculatus for sheep. 4. Sites of carbohydrate and protein digestion as influenced by dietary reactive tannin concentration. Br. J. Nutr., 55, 123-137.

Beauchemin K.A., McGinn S.M., Martinez T.F., McAllister T.A., 2007. Use of condensed tannin extract from quebracho trees to reduce methane emissions. J. Anim. Sci., 85, 1990- 1996.

Belaiche P., 1979. Traité de Phytothérapie et d'Aromathérapie. Tome 1, L'Aromatogramme, 201 , Maloine S.A. Editeur, Paris, France.

Benchaar C., Chouinard P.Y., 2009. Short communication: Assessment of the potential of cinnamaldehyde, condensed tannins, and saponins to modify milk fatty acid composition of dairy cows. J. Dairy Sci., 92, 3392-3396.

Benchaar C., Petit H.V., Berthiaume R., Whyte D., Chouinard P.Y., 2006. Effects of dietary addition of essential oils and monensin premix on digestion, ruminal fermentation, milk production, and milk composition in dairy cows. J. Dairy Sci., 89, 4352-4364.

Benchaar C., Petit H.V., Berthiaume R., Quellet D.R., Chiquette J., Chouinard P.Y., 2007. Effects of essential oils on digestion, ruminal fermentation, rumen microbial populations, milk composition in dairy cows fed alfalfa silage or corn silage. J. Dairy Sci., 90, 886-897.

Benchaar C., McAllister T.A., Chouinard P.Y., 2008. Digestion, ruminal fermentation, ciliate protozoal populations, and milk production from dairy cows fed cinnamaldehyde, quebracho condensed tannin, or Yucca schidigera saponin extracts. J. Dairy Sci., 90, 4765-4777.

Benchaar C., Lettat A., Hassanat F., Yang W.Z., Forster P., Chouinard P.Y., 2012. Eugenol for dairy cows fed low or high concentrate diets: Effects on digestion, ruminal fermentation characteristics, rumen microbial populations and milk fatty acid profile. Anim. Feed Sci. Technol. 178, 139-150.

Bermingham E.N., Hutchinson K.J., Revell D.K. Brookes I.M., McNabb W.C., 2001. The effect of condensed tannins in sainfoin (Onobrychis viciifolia) and sulla (Hedysarum coronarium) on the digestion of amino acids in sheep. Proc. N. Z. Soc. Anim. Prod., 61, 116-119.

Brogna D.M.R., Nasri S., Ben Salem H., Mele M., Serra A., Bella M., Priolo A., Makkar H.P.S., Vasta V., 2011. Effect of dietary saponins from Quillaja Saponaria L. On fatty acid com- position and cholesterol content in muscle longissimus dorsi of lambs. Animal, 7, 11241130

Busquet M., Calsamiglia S., Ferret A., Cardozo P.W., Kamet C., 2005. Effects of cinnamaldehyde and garlic oil on rumen microbial fermentation in a dual flow continuous culture. J. Dairy Sci., $88,2508-2516$.

Busquet M., Calsamiglia S., Ferret A., Kamel C., 2006. Plant extracts affect in vitro rumen microbial fermentation. J. Dairy Sci., 89, 761-771.

Cabiddu A., Molle G., Decandia M., Spada S., Fiori G., Piredda G., Addis M., 2009 Responses to condensed tannins of flowering sulla (Hedysarum coronarium L.) grazed by dairy sheep. Part 2: Effects on milk fatty acid profile. Livest. Sci., 123, 230-240.

Cardozo P.W., Calsamiglia S., Ferret A., Kamel C., 2006. Effects of alfalfa extract, anise, capsicum, and a mixture of cinnamaldehyde and eugenol on ruminal fermentation and protein degradation in beef heifers fed a highconcentrate diet. J. Anim. Sci., 84, 2801-2808.

Chami N., Chami F., Bennis M., Trouillas J. Remmal A., 2004. Antifungal treatment with carvacrol and eugenol on oral candidiasis in immunosuppressed rats. Braz. J. Infect. Dis., 8 , 217-226.

Chaves A.V., Stanford K., Dugan M.E.R., Gibson L.L., McAllister T.A., Van Herk F., Benchaar C., 2008. Effects of cinnamaldehyde, garlic and juniper berry essential oils on rumen fermentation, blood metabolites, growth performance and carcass characteristics of growing lambs. Livest. Sci., 117, 215-224.

Cortes J.E., Moreno B., Pabon M.L., Avila P., Kreuzer M., Hess H.D., 2009. Effects of purified condensed tannins extracted from Calliandra, Flemingia and Leucaena on ruminal an post-ruminal degradation of soybean meal as estimated in vitro. Anim. Feed Sci. Technol., 151, 194-204

Diaz A., Avendano M., Escobar A., 1993 Evaluation of Sapindus saponaria as a defaunating agent and its effects on different rumina digestion parameters. Livest. Res. Rural Develop., 5, 1-6.

Dogna M., 1990. Huiles essentielles, les répertoires de Michel Dogna. Tredaniel G. (Ed). Paris, France, 95p.

Doreau M., Martin C., Eugène M., Popova M. Morgavi D.P., 2011. Leviers d'action pour réduire la production de méthane entérique pour le ruminant. In : Gaz à effet de serre en élevage bovin : le méthane. Doreau M., Baumont R., Perez J.M. (Eds). Dossier, INRA Prod. Anim., 24, 461-474.

Dorman H.J.D., Deans S.G., 2000. Antimicrobial agents from plants: Antimicrobial activity of plant volatile oils. J. Appl. Microbiol., 88, 308-316.

Ellenberger M.A., Rumpler W.V., Johnson D.E., Goodall S.R., 1985. Evaluation of the extent of ruminal urease inhibition by sarsaponin and sarsaponin fractions. J. Anim. Sci., 61 (Suppl. 1), 491

Foo L.Y., Lu Y., McNabb W.C., Waghorn G.C., Ulyatt M.J., 1997. Proanthocyanidins from Lotus pedunculatus. Phytochem., 45, 1689-1696.
Franchomme P., Jollois R., Pénoël D., 1990. L'aromathérapie exactement. Jollois R. (Ed). 447p.

Friedman M., Henika P.R., Mandrell R.E., 2002. Bactericidal activities of plant essential oils and some of their isolated constituents against Campylobacter jejuni, Escherichia coli, Listeria monocytogenes and Salmonella enterica. J. Food Prot., 65, 1545-1560.

Getachew G., Pittroff W., Putnam D.H. Dandekar A., Goyal S., DePeters E.J., 2008. The influence of addition of gallic acid, tannic acid, or quebracho tannins to alfalfa hay on in vitro rumen fermentation and microbial protein synthesis. Anim. Feed Sci. Technol., 140, 444461.

Gill A.O., Holley R.A., 2004. Mechanisms of bactericidal action of cinnamaldehyde against Listeria monocytogenes and of eugenol against L. monocytogenes and Lactobacillus sakei. Appl. Environ. Microbiol., 70, 5750-5755.

Goel G., Makkar H.P.S., Becker K., 2008. Changes in microbial community structure, methanogenesis and rumen fermentation in response to saponin-rich fractions from different plant materials. J. Appl. Microbiol., 105, 770 777 .

Grant W.B., 1998. Milk and other dietary influences on coronary health disease. Alt. Med. Rev., 3, 281-294.

Hernandez-Ochoa L., Vilarem G., 2005. Study of essential oil composition of Origanum dictamnus in differents storage conditions. J. Flavour Fragra., 20, 245-248.

Hess H.D., Kreuzer M., Diaz T.E., Lascano C.E., Carulla J.E., Soliva C.R., 2003. Saponin rich tropical fruits affect fermentation and methanogenesis in faunated and defaunated fluid. Anim. Feed Sci. Technol., 109, 79-94.

Hoffmann L., 2003. Etude du métabolisme des phénylpropanoïdes ; analyse de l'interaction de la caféoyl-coenzyme A 3 O-méthyltransférase (CCoAOMT) avec son substrat et caractérisation fonctionnelle d'une nouvelle acyltransferase ; l'hydroxycinnamoyl-CoA : shikimate/quinate hydroxycinnamoyl transférase (HCT). Thèse de doctorat de l'Université Louis PasteurStrasbourg I, France, 166p.

Hristov A.N., McAllister T.A., Herk F.H.V., Cheng K.-J., Newbold C.J., Cheeke P.R., 1999. Effect of Yucca schidigera on ruminal fermentation and nutrient digestion in heifers. J. Anim. Sci., 77, 2554-2563.

Huang X.D., Liang J.B., Tan H.Y., Yahya R., Ho Y.W., 2011. Effects of Leucaena condensed tannins of differing molecular weights on in vitro $\mathrm{CH} 4$ production. Anim. Feed Sci. Technol., 166-167, 373-376.

Huth P.J., DiRienzo D.B., Miller G.D., 2006. Major scientific advances with dairy foods in nutrition and health. J. Dairy Sci., 89, 12071221 .

Inouye S., Yamaguchi H., Takizawa T., 2001. Screening of the antibacterial effects of variety of essential oils on respiratory tract pathogens, using a modified dilution assay method. J. Infect. Chemother., 7, 251-254.

Jayanegara A., Togtokhbayar N., Makkar H.P.S., Becker K., 2009. Tannins determined 
by various methods as predictors of methane production reduction potential of plants by an in vitro rumen fermentation system. Anim. Feed Sci. Technol., 150, 230-237.

Jayanegara A., Leiber F., Kreuzer M., 2011. Meta-analysis of the relationship between dietary tannin level and methane formation in ruminants from in vivo and in vitro experiments. J. Anim. Physiol. Anim. Nutr., paru en ligne, doi: $10.1111 /$ j.1439-0396.2011.01172.x.

Jeronimo E., Alves A.P., Denttinho M.P.P. Martins S.V., Prates J.A.M., Vasta V., SantosSival J., Bessa R.J.B., 2010. The effect of grape seed extract, Cistus ladanifer I., and vegetable oil supplementation on fatty acid composition of abomasal digesta and intramuscular fat of lambs. J. Agric. Food Chem., 58, 10710-10721.

Knobloch K., Pauli A., Iberl N., Weigand N., Weis H.M., 1989. Antibacterial and antifungal properties of essential oil components. J. Essent. Oil Res., 1, 119-128.

Macheboeuf D., Morgavi D.P., Papon Y., Mousset J.L., Arturo-Schaan M., 2008. Dose-response effects of essential oils on in vitro fermentation activity of the rumen microbial population. Anim. Feed Sci. Technol., 145, 335-350.

Malecky M., Broudiscou L.P., Schmidely P., 2009. Effects of two levels of monoterpene blend on rumen fermentation, terpene and nutrient flows in the duodenum and milk production in dairy goats. Anim. Feed Sci. Technol., 154, 24-35.

McIntosch F.M., Williams P., Losa R., Wallace R.J., Beever D.A., Newbold C.J., 2003. Effects of essential oils on ruminal microorganisms and their protein metabolism. Appl. Environ. Microbiol., 69, 5011-5014.

McNabb W.C., Waghorn G.C., Peters J.S., Barry T.N., 1996. The effect of condensed tannins in Lotus pedunculatus on the solubilization and degradation of ribulose-1,5-bis phosphate carboxylase (EC 4.1.1.39; Rubisco) protein in the rumen and the sites of Rubisco digestion. Br. J. Nutr., 76, 535-549.

Min B.R., Attwood G.T., Reilly K., Sun W., Peters J.S., Barry T.N., McNabb W.C., 2002. Lotus corniculatus condensed tannins decrease in vivo populations of proteolytic bacteria and affect nitrogen metabolism in the rumen of sheep. Can. J. Microbiol., 48, 911-921.

Min B.R., Barry T.N., Attwood G.T., McNabb W.C., 2003. The effect of condensed tannins on the nutrition and health of ruminants fed fresh temperate forages: a review. Anim. Feed Sci. Technol., 106, 3-19.

Min B.R., Pinchak W.E., Fulford J.D., Puchala R., 2005. Wheat pasture bloat dynamics, in vitro ruminal gas production, and potential bloat mitigation with condensed tannins. J. Anim. Sci., 83, 1322-1331.

Min B.R., Solaiman S., Shange R., Eun J.S., 2013. Gastrointestinal bacterial and methanogenic archaea diversity in response to feedind condensed tannins containing pine bark diet to goats using $16 \mathrm{~S}$ rDNA amplicon pyrosequencing. J. Anim. Sci., 91 (E-Suppl. 2/J), J. Dairy Sci., 96 (E-Suppl. 1), pp. 236.

Morsy T.A., Kholif S.M. Matloup O.H., Abdo M.M., El-Shafie M. H., 2012. Impact of anise, clove and juniper oils as feed additives on the productive performance of lactating goats. Intern. J. Dairy Sci., 7, 20-28.
Naumann H.D., Tedeschi L.O., Muir J.P., Lambert B.D., Kothmann M.M., 2013. Effect of molecular weight of condensed tannins from warm-season perennial legumes on ruminal methane production in vitro. Biochem. System. Ecol., 60, 154-162.

Newbold C.J., McIntosh F.M., Williams P., Losa R., Wallace R.J., 2004. Effects of a specific blend of essential oil compounds on rumen fermentation. Anim. Feed Sci. Technol., 114, 105-112.

Noirot V., Bayourthe C., 2008. Effect of aromatic compounds supplementation on protein, fibre and starch ruminal degradation relative to diet composition. Renc. Rech. Rum., 15, 282.

Noirot V., Moncoulon R., Sauvant D., Bayourthe C., 2007. Effet d'une supplémentation en huiles essentielles et composés d'huiles essentielles chez le ruminant : analyse statistique. Revue Med. Vet., 158, 589-597.

Ohene-Adjei S., Chaves A.V., McAllister T.A. Benchaar C., Teather R.M., Forster R.J., 2008. Evidence of increased diversity of methanogenic archaea with plant extract supplementation. Microb. Ecol., 56, 234-242.

Patra A.K., Saxena J., 2009. A review of the effect and mode of action of saponins on microbial population and fermentation in the rumen and ruminant production. Nutr. Res. Rev., 22, 204-219.

Patra A.K., Saxena J., 2010. A new perspective on the use of plant secondary metabolites to inhibit methanogenesis in the rumen. Phytochem., 71, 1198-1222.

Patra A.K., Saxena J., 2011. Exploitation of dietary tannins to improve rumen metabolism and ruminant nutrition. J. Sci. Food Agric., 91, 24-37.

Patra A.K., Yu Z., 2013. Essentials oils modify rumen bacterial compositions in vitro as revealed by microarray analysis. J. Anim. Sci., 91 (E-Suppl. 2/J), J. Dairy Sci., 96 (E-Suppl. 1), pp. 713.

Popova M., Morgavi D.P., Doreau M., Martin C., 2011. Production de méthane et interactions microbiennes dans le rumen. In : Gaz à effet de serre en élevage bovin : le méthane. Doreau M., Baumont R., Perez J.M. (Eds). Dossier, INRA Prod. Anim., 24, 447-460.

Priolo A., Bella M., Lanza M., Galofaro V., Biondi L., Barbagallo D., Ben salem H., Penninsi P., 2005. Carcass and meat quality of lambs fed fresch sulla (Hedysarum coronarium) with or without polyethylene glycol or concentrate. Small Rum. Res., 59, 281-288.

Puchala R., Min B.R., Goetsch A.L., Sahlu T., 2005. The effect of a condensed tannincontaining forage on methane emission by goats. J. Anim. Sci., 83, 182-186.

Reed J.D., 1995. Nutritional toxicology of tannins and related polyphenols forage legumes. J. Anim. Sci., 73, 1516-1528.

Scollan N., Hocquette J.F., Nuernberg K., Dannemberger D., Richardson I., Moloney A., 2006. Innovations in beef production systems that enhance the nutritional and health value of beef lipids and their relationship with meat quality. Meat Sci., 74, 17-33.

Shingfield K.J., Chilliard Y., Toivonen V., Kairenius P., Givens D.I., 2008. Trans fatty acids and bioactive lipids in ruminant milk. In: Bösze Z. (Ed). Bioactive components of milk, Advances in Experimental Medicine and Biology, Springer, New York, NY, 606, 365 .

Sidhu G.S., Oakenfull D.G., 1986. A mechanism fot the hypocholesteroleamic activity of saponins. Br. J. Nutr., 55, 643-649.

Singer M.D., Robinson P.H., Salem A.Z.M., DePeters E.J., 2008. Impacts of rumen fluid modified by feeding Yucca schidigera to lactating dairy cows on in vitro gas production of 11 common dairy feedstuffs, as well as animal performance. Anim. Feed Sci. Technol., 146, 242-258.

Sivakumaran S., Molan A.L., Meagher L.P., Kolb B., Foo L.Y., Lane G.A., 2004. Variation in antimicrobial action of proanthocyanidins from Dorycnium rectum against rumen bacteria. Phytochem., 65, 2485-2497.

Smith A.H., Zoetendal E.G., Mackie R.I., 2005. Bacterial mechanisms to overcome inhibitory effects of dietary tannins. Microb. Ecol., 50, 197-205.

Soyeurt H., Dardenne P., Dehareng F., Bastin C., Gengler N., 2008. Genetic parameters of saturated and monounsaturated fatty acid content and the ratio of saturated to unsaturated fatty acids in bovine milk. J. Dairy Sci., 91, 36113626 .

Tan H.Y., Sieo C.C., Abdullah N., Liang J.B., Huang X.D., Ho Y.W., 2011. Effects of condensed tannins from Leucaena on methane production, rumen fermentation and populations of methanogens and protozoa in vitro. Anim. Feed Sci. Technol., 169, 185-193.

Tavendale M.H., Meagher L.P., Pacheco D., Walker N., Attwood G.T., Sivakumaran S., 2005. Methane production from in vitro rumen incubations with Lotus pedunculatus and Medicago sativa, and effects of extractable condensed tannin fractions on methanogenesis. Anim. Feed Sci. Technol., 123-124, 403419.

Toral P.G., Hervás G., Bichi E., Belenguer A., Frutos P., 2011. Tannins as feed additives to modulate ruminal biohydrogenation: Effects on animal performance, milk fatty acid composition and ruminal fermentation in dairy ewes fed a diet containing sunflower oil. Anim. Feed Sci. Technol., 164, 199-206.

Ultee A., Bennik M.H., Moezelaar R., 2002. The phenolic hydroxyl group of carvacrol is essential for action against the food-borne pathogen Bacillus cereus. Appl. Environ. Microbiol., 68, 1561-1568.

Valdez F.R., Bush L.J., Goetsch A.L., Owens F.N., 1986. Effect of steroidal sapogenins on ruminal fermentation and on production of lactating dairy cows. J. Dairy Sci., 69, 15681575 .

Vasta V., Pennisi P., Lanza M., Barbagallo D., Bella M., Priolo A., 2007. Intramuscular fatty acid composition of lambs given a tanniniferous diet with or without polyethylene glycol supplementation. Meat Sci., 76, 739-745.

Vasta V., Mele M., Serra A., Scerra M., Luciano G., Lanza M., Priolo A., 2009. Metabolic fate of fatty acids involved in ruminal biohydrogenation in sheep fed concentrate or herbage with or without tannins. J. Anim. Sci., 87, 2674-2684. 
Waghorn G.C., Ulyatt M.J., John A., Fisher M.T., 1987. The effect of condensed tannins on the site of digestion of amino acids and other nutrients in sheep fed on lotus. Br. J. Nutr., 57, $115-126$

Waghorn G.C., Shelton I.D., McNabb W.C., 1994. The effect of condensed tannin in Lotus pedunculatus on nutritive value for sheep. 2. Nitrogenous aspects. J. Agric. Sci., 123, 109-119.

Wallace R.J., McPherson C.A., 1987. Factors affecting the rate of breakdown of bacterial protein in rumen fluid. Br. J. Nutr., 58, 313-323.

Wallace R.J., Arthaud L., Newbold C.J., 1994. Influence of Yucca schidigera extraction on ruminal ammonia concentrations and ruminal microorganisms. Appl. Environ. Microbiol., 60, 1762-1767.

Wang Y., Douglas G.B., Waghorn G.C., Barry T.N., Foote A.G., Purchas R.W., 1996. Effect of condensed tannins upon the performance of lambs grazing Lotus corniculatus and lucerne (Medicago sativa). J. Agric. Sci., $126,87-98$

Wang Y., McAllister T.A., Yanke L.J., Xu Z.J. Cheeke P.R., Cheng K.J., 2000. In vitro effects of steroidal saponins from Yucca schidigera extract on rumen microbial protein synthesis and rumen fermentation. J. Sci. Food Agric. $80,2114-2122$.
Wina E., Muetzel S., Becker K., 2006. The dynamics of major fibrolytic microbes and enzyme activity in the rumen in response to short- and long-term feeding of Sapindus rarak saponins. J. Appl. Microbiol., 100, 114-122.

Zhou Y.Y., Mao H.L., Jiang F., Wang J.K., Liu J.X., McSweeney C.S., 2011. Inhibition of rumen methanogenesis by tea saponins with reference to fermentation pattern and microbial communities in $\mathrm{Hu}$ sheep. Anim. Feed Sci. Technol., 166-167, 93-100.

\section{Résumé}

Les extraits de plantes représentent un groupe complexe de substances dont les propriétés peuvent être utilisées pour manipuler le fonctionnement du rumen. Parmi eux, les tannins condensés, les huiles essentielles et les saponines ont été largement évalués pour leurs effets bactéricides/bactériostatiques. La variété de structure chimique des tannins condensés est, sans doute, à l'origine de leur différence de réactivité mais aussi d'une activité différente vis-à-vis des microorganismes du rumen. De façon générale, la croissance bactérienne est d'autant plus inhibée que la concentration en tannins condensés dans le milieu est élevée. Si les tannins condensés inhibent l'activité des archées méthanogènes, ils seraient sans effet sur les protozoaires. Généralement, les tannins condensés conduisent à une diminution de la concentration en azote ammoniacal dans le milieu ruminal mais n'affectent pas la concentration en acides gras volatils totaux. Si à dose élevée, l'effet est plus marqué in vitro qu'in vivo, à dose identique, l'amplitude de la réponse est différente selon la source de tannins condensés. En ce qui concerne l'action des tannins condensés sur la méthanogenèse, l'effet généralement observé, tant in vitro qu'in vivo, est une diminution de la production de $\mathrm{CH}_{4}$ bien que l'amplitude de la réponse soit variable et dépende de plusieurs facteurs que les études in vitro permettent de mieux cerner. Les effets principaux des huiles essentielles dans le rumen consistent en une réduction de la dégradation des protéines et de l'amidon et une inhibition de la dégradation des acides aminés, en raison de l'action sélective sur certains micro-organismes du rumen. Le pouvoir bactéricide des huiles essentielles vis-à-vis des bactéries (pathogènes ou ruminales) est lié à la structure chimique des molécules aromatiques qui les composent. Elles inhibent la croissance de la plupart des cultures pures bactériennes du rumen à des concentrations inférieures à $100 \mathrm{ppm}$; certaines espèces pouvant s'adapter, ce qui explique la diminution voire l'absence d'effet souvent observé in vivo. Certains composés aromatiques ont la capacité de réduire la production de méthane dans le rumen. En revanche, les effets des saponines dans le rumen sont moins nets, en raison probablement du développement de populations microbiennes capables de les dégrader et/ou de l'adaptation des microorganismes à ces extraits de plante. Par ailleurs, en l'état actuel des connaissances, il est impossible de conclure quant à l'effet des extraits végétaux sur la qualité lipidique des produits animaux. Des essais complémentaires conduits in vivo et à long terme restent indispensables pour vérifier les effets observés, dans des conditions d'utilisation plus variées, mais aussi pour s'assurer de l'absence de résidus dans les produits animaux et de leur innocuité pour le consommateur.

\section{Abstract}

\section{Plant extracts in ruminants: effects on fermentation in the rumen and on lipid quality in animal products}

Plant extracts are a complex group of substances whose properties can be used to manipulate the functioning of the rumen. Among them, condensed tannins, essential oils and saponins have been widely tested for their bactericidal/bacteriostatic effects. The variety of chemical structure of condensed tannins is probably at the origin of their difference of reactivity but also of a different activity on ruminal microorganisms. Generally speaking bacterial growth is more inhibited when the condensed tannins concentrations are raised. Condensed tannins inhibit the activity of methanogenic Archaea, and their effects on protozoa are different depending on the species. Generally, condensed tannins lead to a decrease of the concentration of ammoniacal nitrogen in the rumen but do not affect the concentration of total volatile fatty acids. At high concentrations, the effect is more pronounced in vitro than in vivo. But at a similar concentration, the amplitude of the response is different, depending on the source of condensed tannins. Their effect on methanogenesis, generally observed in vitro as well as in vivo, is a decrease in methane production, with a variation according to the incubation time, the total content of condensed tannins and the concentration. The main effects of the essential oils in the rumen are a reduction of degradation of protein and starch and an inhibition of the degradation of the amino acids, due to the selective action of certain rumen microorganisms. The bactericidal effect of essential oils on bacteria (pathogenic or ruminal) is related to the chemical structure of their aromatic molecules. At concentrations below $100 \mathrm{ppm}$, they inhibit the growth of most pure bacterial ruminal cultures. However, the adaptation of some bacterial species may explain the decrease or the lack of effect often observed in vivo. Some essential oils appear to have the potential to inhibit methane production in the rumen. However, the effects of saponins in the rumen are less clear, probably due to the development of microbial populations with a saponin degradation capacity, and/or adaptation of the concerned microorganisms to these plant extracts. Moreover, in the present state of knowledge, it is impossible to conclude on the effect of plant extracts on the lipid quality of animal products. Additional in vivo and long-term tests remains essential to verify the observed effects in more varied conditions. These tests should also make sure that no residues remains in the animal products and, if yes, that these residues will not induce any safety problem for consumers.

BAYOURTHE C., ALI-HAIMOUD-LEKHAL D., 2014. Les extraits de plantes chez le ruminant : effets sur les fermentations dans le rumen et la qualité lipidique des produits animaux. INRA Prod. Anim., 27, 317-328. 